\title{
Stereoselective Radical Reactions with Chiral Acrylamides and Methacrylamides
}

\author{
Bernd Glese*, Ursula Hotfimann, Martin Roth, Andreas Velt, Carollne Wyse, Margaretha Zehnder, \\ and Hendrik Zlpee
}

Department of Chemistry, University of Basel, St. Johanns Ring 19, CH-4056 Basel, Switzerland

\begin{abstract}
Stereoselective radical reactions are observed with chiral methacrylarides 3 and 7 , although the $\pi-8 y s t e m s$ are twisted to a considerable extent.
\end{abstract}

Chiral amide groups can act as powertul auxiliaries in stereoselective radical reactions. ${ }^{1}$ The reasons for their success may be explained by alkene 1 and radical 2 adopting preferred conformations in which the conjugated system is planar, and the small hydrogen atom adjacent to the amide group is syn to the amine. In this conformation of the $\mathrm{C}_{2}$-symmetrical dimethylpyrrolidine, one of the two methyl groups is closer to the carbon atom $\alpha$ to the carbonyl group. Only this adjacent methyl group shields the $\mathrm{sp}^{2}$-center effectively. ${ }^{2}$<smiles>C=CC(=O)N1[C@@H](C)CC[C@H]1C</smiles>

1<smiles>C=CC(=O)N1[C@@H](C)[C@H](C)CC[C@H]1C</smiles>

$3 \mathbf{a}$<smiles>[2H]CCC(=O)N1[C@H](C)CC[C@H]1C</smiles>

2<smiles>C=C(C)C(=O)N1[C@@H](C)[C@H](C)CC[C@H]1C</smiles>

$3 b$

Substitution of the hydrogen at the $\alpha$-carbon atom by an alkyl group should have a considerable effect, because in both planar conformations 39 and $3 b$ a carbon group is now in the sterically demanding location (syn to the amine). In fact, the $X$-ray crystal structure of the substituted alkene 4 shows that the $\alpha, \beta$-unsaturated system is twisted with an out of plane angle of $119^{\circ}$ (Figure 1). 3 Thus, the steric repulsion in the planar conformation is a more important factor than the stabilization by conjugation between the C,C- and C,O- $\pi$ bonds. 4 


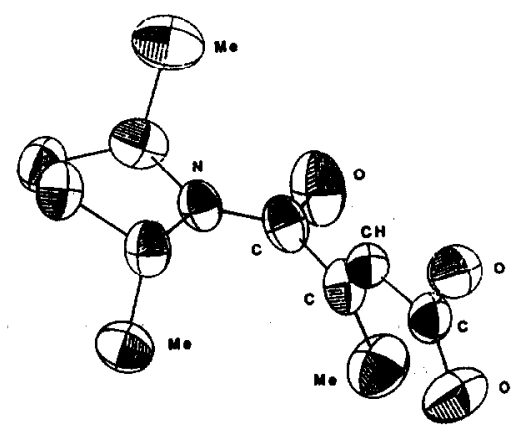

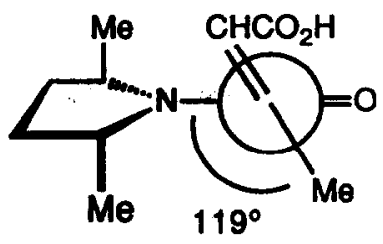

4

Figure 1. ORTEP-Plot and Newman projection of alkene 4.

This twisting has a dramatic effect on the reaction rate. The addition of a tert-butyl radical to methyl acrylamide 3 is 37 times slower than to acrylamide $1\left(20^{\circ} \mathrm{C}\right) .6$ The intermediate of this reaction is radical 5. According to AM1 calculations radical 5 is also twisted with $5 a$ and $5 b$ found as minimum conformations. 8

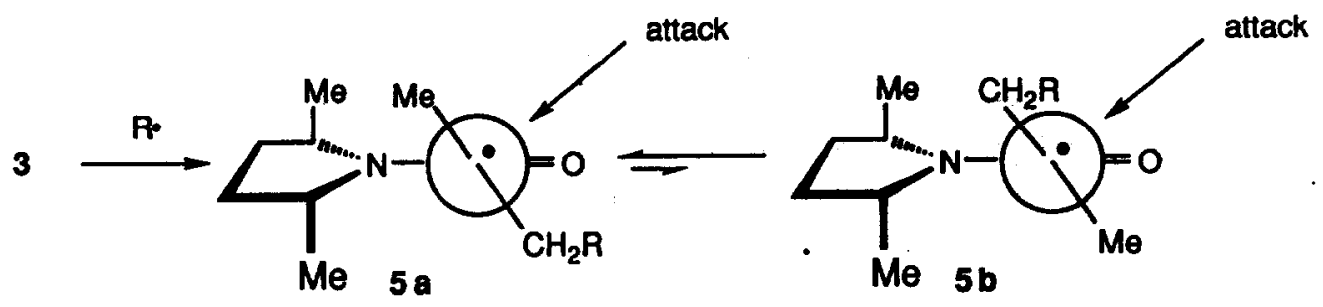

We were now interested to learn how this twisting influences the stereoselectivity of the radical hydrogen atom abstraction. Using the mercury or the tin method $^{9}$ the radical addition to methyl acrylamide 3 afforded $6 a$ as the main product.<smiles>C=C(C)C(=O)N1[C@@H](C)CC[C@H]1C</smiles>

3

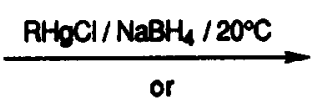

$\mathrm{RBr} / \mathrm{Bu} \mathrm{SnH} / \mathrm{hv} / 20^{\circ} \mathrm{C}$

(30-75\%)<smiles>[R]C[C@H](C)C(=O)N1[C@H](C)CC[C@H]1C</smiles>

6 a
$6 \mathbf{b}$

R: $\quad t-\mathrm{C}_{4} \mathrm{H}_{9} \quad 90: 10\left(93: 7,-10^{\circ} \mathrm{C}\right)$

R: $\quad c-\mathrm{C}_{6} \mathrm{H}_{11} \quad 80: 20$

R: $\mathrm{CH}_{3} \quad 67: 33$

Thus, despite the twisting, the hydrogen atom abstraction step remains stereoselective. The stereoselectivity can best be explained by the preferred conformation 5a, where reaction occurs anti to the shielding pyrrolidine group. In conformer 5a the bulky $\mathrm{RCH}_{2}$ substituent is further away from the sterically demanding pyrrolidine auxiliary and shodild be more stable than conformer $\mathbf{5 b}$. 
Both conformers are attacked anti to the pyrrolldine group and the stereoselectivity therefore depends on the equilibrium between $5 \mathrm{~s}$ and $5 \mathrm{~b}$. The bulkjer the group $\mathrm{A}$ is, the more conformer 5a should be tavored. In accord with thie model the ratio 60 : 6b increaces at $20^{\circ} \mathrm{C}$ from $67: 33$ for $\mathrm{R}=\mathrm{CH}_{3}$ to $80: 20$ for $\mathrm{R}=C_{-}-\mathrm{C}_{6} \mathrm{H}_{11}$, and $90: 10\left(93: 7,-10^{\circ} \mathrm{C}\right)$ for $\mathrm{A}=t-\mathrm{C}_{4} \mathrm{H}_{9}$. A similar trend can also be observed with bis(methoxymethyl)pyrrolidine as auxlliary. 10

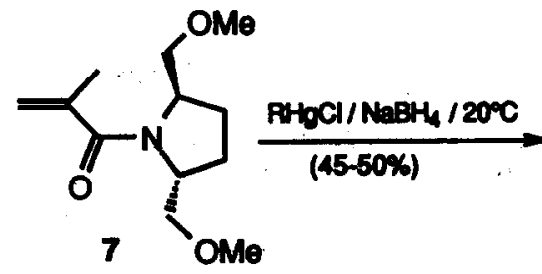

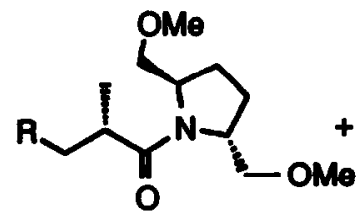

$8 \mathbf{a}$<smiles>[R]C[C@H](C)[C@H](O)N1[C@H](COC)CC[C@H]1COC</smiles>

$8 \mathbf{b}$

\section{R: $\mathrm{FC}_{4} \mathrm{H}_{9} \quad 9: 91$ \\ R: $\quad{ }^{-}-\mathrm{C}_{8} \mathrm{H}_{11} \quad 20: 80$}

In contrast to the radical reactions with methyl acylamides 3 and 7, the acrylamide 9 shows no influence of group $R$ on the diastereoselectivity. At $15^{\circ} \mathrm{C}$, the diastereoselectivity is about $85: 15$ for $\mathrm{R}=\mathrm{t}-\mathrm{C}_{4} \mathrm{H}_{9}, c_{-}-\mathrm{C}_{6} \mathrm{H}_{11}$, and $\mathrm{CH}_{3} .12$ The intermediate of this reaction is the radical 10, where the bulk of the prochiral $\mathrm{CH}_{2} \mathrm{R}$-group plays no role in the stereochemical process. The stereochemistry is only influenced by the methyl or methoxymethyl group at the chiral center of the pyrrolidine auxlliary.

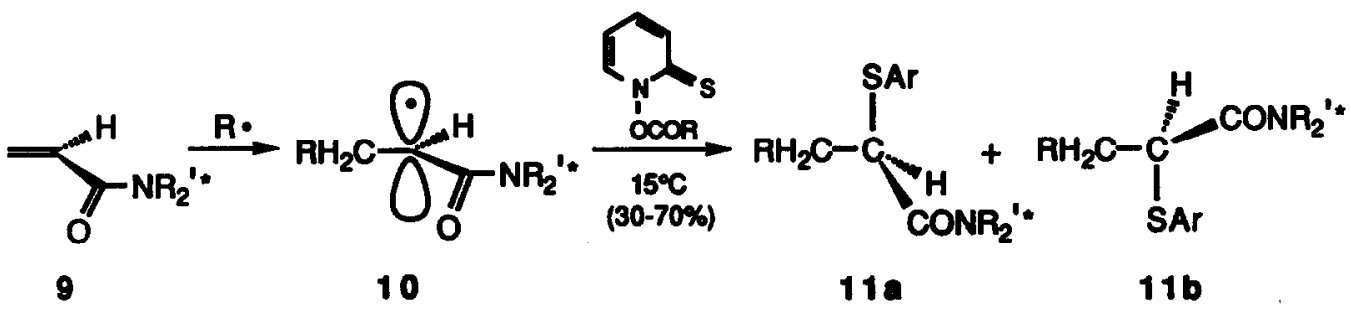

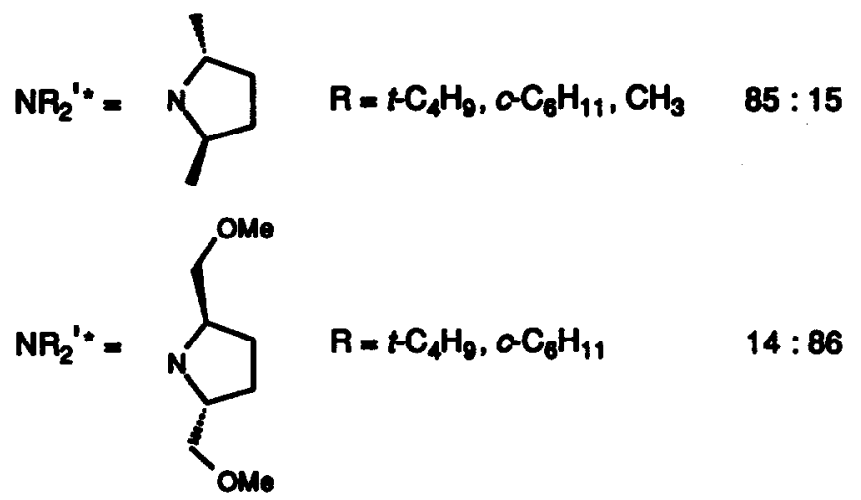


Concluslon: Although the tertiary radical 5 is twisted to a considerable extent it is attacked from the same side as the non-twisted secondary radical 10 . The added radical $R$ influences the stereoselectivity of $\mathbf{5}$ because it affects the equilibrium between $5 \mathrm{a}$ and $\mathbf{5 b}$.

Acknowledgement: This work was supported by the Swiss National Science Foundation.

\section{References and Notes}

1. For a review see: N.A. Porter, B. Giese, D.P. Curran, Acc.Chem.Res. 1991, 24, 296.

2. N.A. Porter, W.X. Wu, A.T. McPhall, Tetrahedron Lett. 1901, 32, 707.

A. Veit, R. Lenz, M.E. Seiler, M. Neuburger, M. Zehnder, B. Giese, Holv.Chim.Acta in press.

3. The atomic coordinates for 4 and $11 \mathrm{~b}$ are avallable on request from the Director of the Cambridge Crystallographic Data Centre, University Chemical Laboratory, Lensfield Road, Cambridge CB2 1EW. Any request should be accompanied by the full literature citation for this communication.

4. Twisted conformations of methacrylamides have also been observed by $W$. Oppolzer et al.5a and D.P. Curran of al. 50 in related systems.

5. a) W. Oppolzer, G. Poll, C. Starkman, G. Bernadelli, Tetrahedron Lett. 1988, 29, 3559; b) D.P. Curran, T.A. Heffner, J.Org.Chem. 1900, 55, 4585.

6. The rel. rates were measured under pseudo-first order conditions.7 A similar rate decrease with a twisted methacrylamide was obeerved by D.P. Currarr of al.5 in cycloaddition reactions.

7. B. Giese, G. Kretzschmar, J. Molxner, Chem.Ber. 19e9; 113, 2787.

8. According to the AM1 calculations the energy differences between the conformations $5 a$ and $5 b$ is less than $1 \mathrm{kcal} / \mathrm{mol}$. For AM1 calculations se日: M.J.S. Dewar, E.G. Zoebisch, E.F. Healy, J.J.P. Stewart, J.Am.Chem.Soc. 1885, 107, 3902.

9. B. Giese, Angew.Chem.Int.Ed.Engl. 1995, 24, 553.

10. The structure of products $6 a, b$ and $8 a, b$ were elucidated via ionic methylation of the saturated amide 12 via the method of Katsuki. ${ }^{11}$

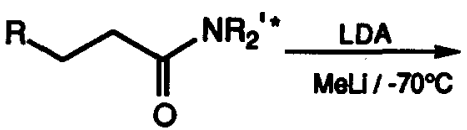

12

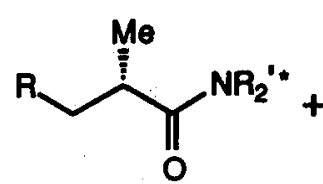

$6 a$ or $7 a$<smiles>[R]C[C@@H](C)C(=O)[18OH]</smiles>

$6 b$ or $7 b$

At $-78^{\circ} \mathrm{C}$ the ionic methylation of $12\left(\mathrm{HNR}_{2}{ }^{1 *}=\right.$ dimethylpyrrolidine) occurs with a d.e. of $97 \%$ $\left(\mathrm{R}=\mathrm{F}_{4} \mathrm{H}_{9}\right), 88 \%\left(\mathrm{R}=\mathrm{CC}_{6} \mathrm{H}_{11}\right)$ and $89 \%\left(\mathrm{R}=\mathrm{CH}_{3}\right)$. With bis(methoxymethyl)pyrrolidine as auxiliary only one isomer can be observed.

11. Y. Kawanami, Y. Ito, T. Kitagawa, Y. Tamiguchi, I. Katsuki, M. Yamaguchi, Tetrahedron Lett. 1984, 25, 857.

12. The reaction of the tert-butyl radical with $9\left(\mathrm{HNR}_{2}{ }^{* *}=\right.$ dimethylpyrrolidine $)$ has already been described: B. Giese, M. Zehnder, M. Roth, H.G. Zeitz, J.Am.Chem.Soc. 1990, 112, 6741. The structure elucidation of product $11 \mathrm{~b}\left(\mathrm{HNR}_{2}{ }^{\prime *}=\right.$ bis (methoxymethyl)pyrrolidine, $\left.\mathrm{R}=t-\mathrm{C}_{4} \mathrm{H}_{9}\right)$ was carried out via X-ray analysis. ${ }^{3}$ 